\title{
Berufliche Vorsorge BVG
}

\section{Vernachlässigen Sie nicht Ihr wichtigstes Altersvorsorgeinstrument!}

Obwohl der grösste Teil der privaten Vermögen bei einer Pensionskasse liegt, wird dieser Bereich oft vernachlässigt. Es lohnt sich, regelmässig zu überprüfen, welche Lösung am besten zu Ihnen passt. Nachfolgend sehen Sie eine Checkliste der wichtigsten Punkte, welche auf Sie abgestimmt werden sollten:

\begin{tabular}{|c|c|c|}
\hline$\square$ & Höhe der Sparbeiträge & $\begin{array}{l}\text { Je nach Vorsorgeplan können Sparbeiträge von bis zu } 25 \% \text { des versicherten Einkommens ver- } \\
\text { einbart werden. Durch eine Erhöhung können Steuern gespart werden. Zudem werden neue } \\
\text { Einkaufsmöglichkeiten geschaffen. }\end{array}$ \\
\hline$\square$ & Höhe der Risikoleistungen & $\begin{array}{l}\text { Einige möchten im Todesfall Ihre Familie absichern, andere benötigen eine höhere Rente bei } \\
\text { Erwerbsunfähigkeit. Welche Bedürfnisse haben Sie? }\end{array}$ \\
\hline$\square$ & Verzinsung & $\begin{array}{l}\text { Grundsätzlich wird Ihr Vorsorgekapital zum BVG-Zinssatz von 2,00\% verzinst. Wie sieht es } \\
\text { aber im überobligatorischen Bereich aus? }\end{array}$ \\
\hline$\square$ & $\begin{array}{l}\text { Anlageform des } \\
\text { Vorsorgekapitals }\end{array}$ & $\begin{array}{l}\text { Kennen Sie die Möglichkeiten einer renditeorientierten Anlage Ihres überobligatorischen Vor- } \\
\text { sorgeguthabens? }\end{array}$ \\
\hline$\square$ & $\begin{array}{l}\text { Risiko- und } \\
\text { Verwaltungskosten }\end{array}$ & $\begin{array}{l}\text { Wie hoch sind die Risiko- und Verwaltungskosten Ihrer Stiftung? Gibt es noch günstigere } \\
\text { Lösungen? }\end{array}$ \\
\hline$\square$ & Umwandlungssatz & $\begin{array}{l}\text { Welcher Umwandlungssatz für die Rentenleistung wendet Ihre Stiftung an? Ist im überobliga- } \\
\text { torischen Bereich ein tieferer Satz vorgesehen? }\end{array}$ \\
\hline$\square$ & Einkaufsmöglichkeiten & $\begin{array}{l}\text { Verfügen Sie noch über Einkaufspotential? Wie kann dieses erhöht werden, und wann sind } \\
\text { Einkäufe aus steuerlicher Sicht am interessantesten? }\end{array}$ \\
\hline$\square$ & Vermögensverteilung & $\begin{array}{l}\text { Kennen Sie die genaue Aufteilung Ihres Vermögens und wissen Sie, wie viel Prozent davon } \\
\text { in der Pensionskasse sind? }\end{array}$ \\
\hline
\end{tabular}

\section{Handeln Sie heute}

Die meisten BVG-Anschlussverträge sind jeweils per Ende Juni auf Ende Jahr kündbar. Damit genügend Zeit zur Suche der für Sie optimalen Lösung bleibt, empfehlen wir Ihnen, sich jetzt beraten zu lassen. Zögern Sie deshalb nicht und senden Sie uns noch heute den untenstehenden Talon, damit der FMH Insurance Services-Berater aus Ihrer Region mit Ihnen Kontakt aufnehmen kann.

\section{Antworttalon}

Bitte einsenden oder per Fax an: 0319595010

Vorname/Name

Adresse

PLZ/Ort

\section{Geburtsdatum}

Telefon Privat/Geschäft

Beste Zeit für einen Anruf

E-Mail-Adresse

Ich möchte meine berufliche Vorsorge BVG überprüfen lassen. Bitte rufen Sie mich für einen Termin an.

Ich interessiere mich auch noch für:

\begin{tabular}{|c|c|c|}
\hline Krankenkasse & ○ & Pensionsplanung \\
\hline Säule 3a & O & Hausratversicherung \\
\hline Finanz-/Steuerplanung & O & Berufshaftpflichtversicherung \\
\hline
\end{tabular}

